\title{
管 \\ OUTLIERS SÃO OUTSIDERS? PERFIL DOS DEPUTADOS ESTADUAIS "HEAVY USERS” DE MÍDIAS DIGITAIS NA LEGISLATURA 2019-2023
}

\author{
ARE THE OUTLIERS, OUTSIDERS? PROFILE OF STATE DEPUTIES "HEAVY USERS" \\ OF DIGITAL MEDIA IN THE LEGISLATURE 2019-2023
}

\author{
¿LOS OUTLIERS SON OUTSIDERS? PERFIL DE LOS DIPUTADOS ESTADUALES \\ “HEAVY USERS” DE MEDIOS DIGITALES EN LA LEGISLATURA 2019-2023
}

\author{
Sérgio Braga \\ Diogo Tavares ${ }^{2}$ \\ Rafael Linhares e Padilha ${ }^{3}$ \\ Márcio Giovanni Macedo ${ }^{4}$
}

Resumo: O objetivo deste artigo é fazer um estudo do uso das midias digitais pelos deputados estaduais brasileiros na legislatura 2019-2023. Procuraremos responder à seguinte questão: os parlamentares intensivos no uso das midias digitais em cada unidade da federação brasileira (outliers) podem também ser considerados "outsiders", ou seja, parlamentares novatos na atividade política? Para verificar este fenômeno analisaremos o uso das duas midias digitais públicas mais utilizadas pelos deputados estaduais brasileiros no período 20192020, ou seja, Facebook e Instagram, verificando se este uso está associado a certas características da carreira política dos deputados. Os resultados indicam que esse fenômeno ocorre no Instagram, mas não no Facebook, ou seja, mídias sociais públicas de uso mais recente são usadas com mais intensidade por parlamentares "outsiders".

Palavra-chave: Comunicação pública parlamentar; Elites políticas; Outsiders; Outliers; Representação política.

\begin{abstract}
The purpose of this article is to make a study about the use of digital media by Brazilian state deputies in the 2019-2023 legislature. We will try to answer the following question: can parliamentarians intensive in the use of digital media in each unit of the Brazilian federation (outliers) also be considered "outsiders", that is, parliamentarians who are new to political activity? To verify this phenomenon, we will focus on analyzing the use of the two public digital media most used by Brazilian state deputies in the 20192020 period: Facebook and Instagram, checking whether this use is associated with certain characteristics of the political career of the deputies. The results indicate that this phenomenon occurs on Instagram, but not on Facebook, that is, more recently used public social media are used more intensively by parliamentarians' "outsiders".
\end{abstract}

Keywords: Parliamentary public communication; Political elites; Outsiders; Outliers; Political representation.

Resumen: El propósito de este artículo es hacer un estudio del uso de los medios digitales por los diputados

\footnotetext{
${ }^{1}$ Sérgio Braga é Doutor em Desenvolvimento Econômico pelo IE Unicamp, Professor de Ciência Política do Programa de Pós-Graduação em Ciência Política (PPGCP) da UFPR, e bolsista produtividade nível 2 do CNPq. E-mail: sssbraga@gmail.com.

${ }^{2}$ Diogo Tavares é doutorando em Ciência Política pelo PPGCP-UFRP. E-mail: di_2712@hotmail.com

${ }^{3}$ Rafael Linhares e Padilha é Bolsista de Iniciação Científica PIBIT pelo CNPq. Graduando em Ciências Sociais com ênfase em Ciência Política pela Universidade Federal do Paraná, Email: rafaellinhares3030@gmail.com, https://orcid.org/0000-0003-3415-844

${ }^{4}$ Márcio Giovanni Macedo é Mestrando em Ciência Política no PPGCP-UFPR.
} 
estatales brasileños en la legislatura 2019-2023. Intentaremos responder a la siguiente pregunta: ¿los parlamentarios que son intensivos en el uso de los medios digitales en cada unidad de la federación brasileña (outliers) también pueden ser considerados “outsiders", es decir, parlamentarios que son nuevos en la actividad política? Para verificar este fenómeno, nos centraremos en analizar el uso de los dos medios digitales públicos más utilizados por los diputados de estado brasileños en el período 2019-2020: Facebook e Instagram, comprobando si este uso está asociado con ciertas características de la carrera política. de los diputados. Los resultados indican que este fenómeno ocurre en Instagram, pero no en Facebook, es decir, las redes sociales públicas utilizadas más recientemente son utilizadas de manera más intensiva por parlamentarios "outsiders".

Palabras-clave: Comunicación pública parlamentaria; Élites políticas; Outsiders; Outliers; Representación política.

\section{Introdução: outliers e outsiders como problema de pesquisa ${ }^{5}$}

Nos últimos anos, tem sido intenso o debate sobre o uso de mídias digitais pelos parlamentares, sob as mais diversas óticas. Isso tem razão de ser, pois é evidente para qualquer observador atento das elites políticas o grande uso das mídias digitais pelos membros do parlamento, tanto em períodos eleitorais, como não eleitorais, e sua incorporação sistemática nas estratégias de comunicação pública dos representantes. No entanto, no campo de estudos sobre internet e política, o uso das mídias digitais pelas elites políticas das unidades subnacionais ainda tem sido pouco explorado, tendo boa parte dos artigos publicados sobre a temática se concentrando em nível nacional. Esse processo é inusitado, considerando a importância desta rede social para diversos atores políticos também em escala subnacional, onde há maior proximidade das elites com sua audiência, elites estas que estão empregando cada vez mais estas plataformas como espaços de autopromoção, disseminação de narrativas e interação com suas bases de apoio (BARROS et al, 2015; ALMEIDA, H. et al., 2017, 2020; BRAGA; CRUZ, 2017; REHBEIN-SATHLER; FERREIRA, 2020).

Por outro lado, estudos que abordam a temática de carreira política dos parlamentares são cada vez mais frequentes na literatura da ciência política brasileira, com um corpus crescente de trabalhos analisando a carreira política dos parlamentares (MIGUEL, 2003; CODATO, LORENCETTI; PRATA, 2020). Um tema que tem reaparecido com frequência nessa literatura, tendo em vista o contexto de realização de "eleições críticas" em diversos países, que mudam a correlação de forças entre atores políticos relevantes, é o tema dos outsiders, ou seja, das novas lideranças políticas que se elegeram a determinados cargos políticos no contexto de emergência de novas elites em diversos países recentemente. Como observado pela literatura, este processo está fortemente associado à emergência de líderes políticos "populistas", via de regra ancorados no uso intensivo de novas mídias digitais e com uma estratégia discursiva "antisistema" (BARR, 2009; DONATELLO; LEVITA, 2017).

\footnotetext{
${ }^{5}$ Este artigo foi elaborado no âmbito do projeto de pesquisa "Profissionalização política, tecnologias digitais e as funções desempenhadas pelos e-parlamentos: um estudo comparado das Assembleias e Câmaras Legislativas brasileiras (20192023)", financiado pelo CNPq (Chamada CNPq 06/2019 - Bolsas de Produtividade em Pesquisa, processo 311675/20190). Agradecemos aos bolsistas Maria Cristina Gomes Cassaro (PIBIC-UFPR), Hanna Marcon (PIBIT-UFPR), João Felipe Kahali (Fundação Araucária-UFPR) e Mayara Gomes (pesquisadora voluntária-UFPR) que auxiliaram no processo de coleta de dados para elaboração deste artigo no período de junho a setembro de 2020.
} 
Nesse contexto, cabe formular as seguintes indagações: qual a relação das mídias digitais com a emergencia dessas novas lideranças políticas, qualificadas por diversos autores como "outsiders" num sentido amplo do termo? Existe alguma relação entre os padrões de carreira política parlamentar e a alta quantidade de seguidores em redes sociais online, com parlamentares tidos como "novatos" usando de maneira mais intensa as mídias digitais, vis-à-vis os "estabelecidos"? Essas são as questões mais gerais que orientaram a elaboração deste trabalho. Nosso objetivo é verificar se ocorre, em escala subnacional no Brasil, o fenômeno observado em alguns outros contextos, de emergência de novas lideranças que acumularam capital político através de sua atuação nas mídias digitais (PURBA; ASIRVATHAM; MURUGESAN, 2020).

Assim, o objetivo básico deste texto é realizar uma investigação sobre o uso das tecnologias digitais pelos deputados estaduais brasileiros correspondentes à legislatura de 2019-2023, examinando a quantidade de seguidores nas redes digitais públicas mais utilizadas pelos parlamentares (Facebook, Instagram, Twitter e Youtube, além de Websites e presença na Wikipedia) e cruzando tais dados com informações sobre suas carreiras no parlamento. Para cumprir este objetivo, fizemos um levantamento do uso das principais ferramentas da internet por 1065 deputados estaduais brasileiros (1059 eleitos originalmente, e 6 outros empossados ao longo da legislatura) no período compreendido entre os anos de 2019 e 2020 e procuramos relacionar estes dados com as informações sobre padrões de carreira constante no site do TSE e nos websites das assembléias legislativas brasileiras e a Câmara Distrital do DF.

Para abordar estes problemas, organizaremos nossa exposição da seguinte forma: a) inicialmente, forneceremos algumas informações básicas sobre o uso das principais ferramentas de internet e midias digitais por 1059 parlamentares atuantes durante a legislatura, e definiremos melhor os conceitos de outliers e outsiders empregados no presente artigo, bem como a importância deste debate para a ciência política contemporânea; b) em seguida, analisaremos os dados sobre os outliers e outsiders no período pesquisado, e procuraremos aprofundar a abordagem de algumas questões de pesquisa e apresentar algumas proposições básicas que estruturam o presente enfoque; c) por fim, buscamos extrair inferências gerais do presente artigo e indicar problemas a serem tratados de maneira mais aprofundada em outras etapas da presente pesquisa.

\section{0 uso das midias digitais pelos deputados estaduais no período 2019-2020 e o problema dos outliers e dos outsiders}

Em primeiro lugar, devemos expor nosso universo empírico de pesquisa, composto por 1065 deputados estaduais eleitos para a legislatura 2019-2023 empossados no período. Como pode ser visto pelo gráfico abaixo, ao todo estiveram representados 32 partidos nos parlamentos estaduais durante o período pesquisado, com um quadro partidário bastante fragmentado que dificulta a utilização dos partidos individualmente considerados como unidade de análise, sem o emprego de 
algum critério de agregação. Pelo gráfico, podemos observar uma representação partidária bastante dispersa sem nenhum partido claramente dominante nos parlamentos estaduais.

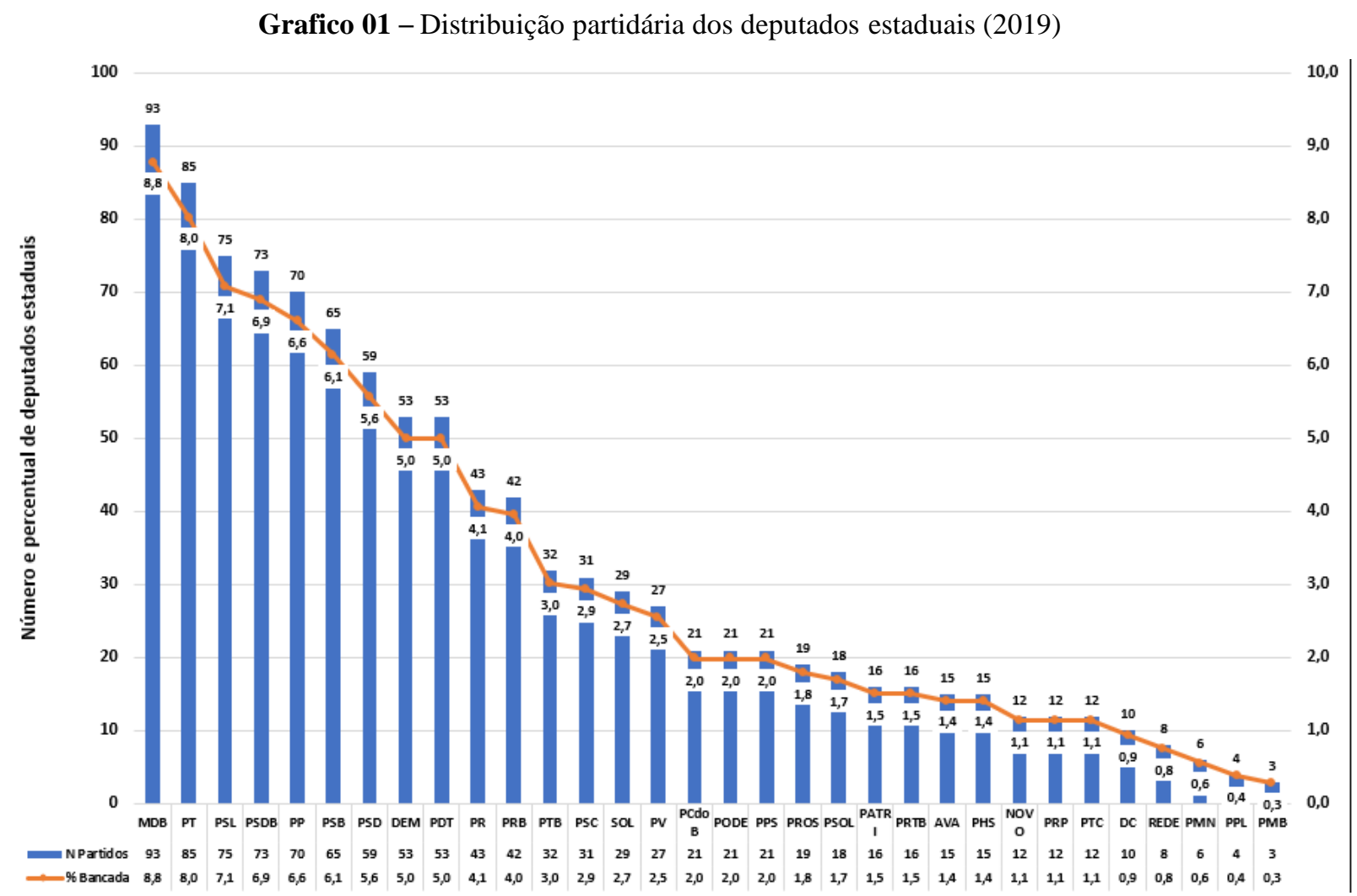

Fonte: Base de dados do grupo de pesquisa, 2021.

Os cinco principais partidos são, por gradiente de bancada, o MDB (com 93 deputados ou 8,8\% do total de parlamentares), o PT $(85=8,0 \%)$, o PSL (75), o PSDB (73), PP (70) e assim sucessivamente. Assim, observamos que, apesar da ascensão de partidos associados ao bolsonarismo, como o PSL, a estrutura partidária tradicional de partidos fisiológicos de centro-direita manteve-se forte nas assembléias legislativas, com a manutenção ou queda menor que a esperada das bancadas de partidos mais programáticos tais como o PSDB, o PT e o DEM, apesar do desgaste sofrido por estes partidos no plano federal. No tocante ao uso das principais mídias sociais pelos deputados, esta informação é fornecida pelo seguinte gráfico: 
Grafico 02 - Uso das principais midias digitais pelos deputados estaduais $(2020$ - n = 1059) .

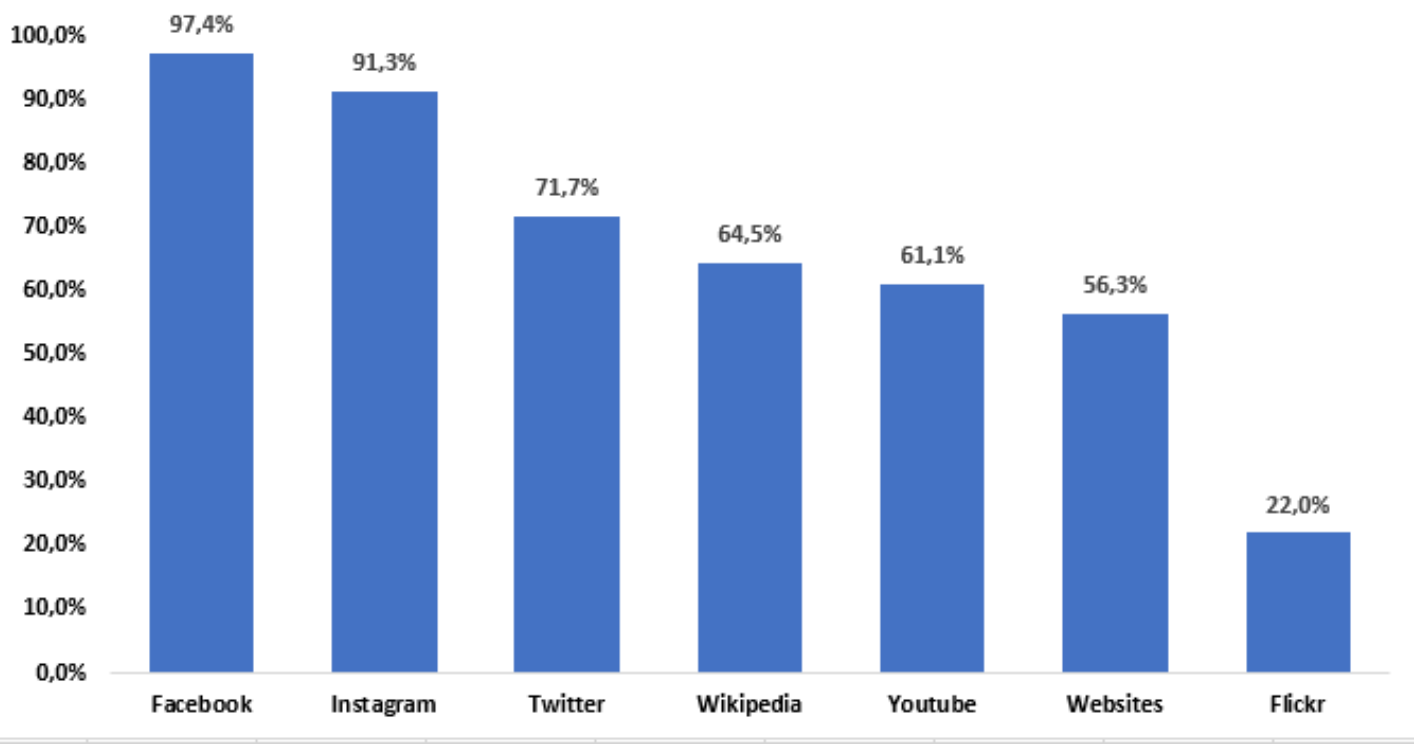

Fonte: Base de dados do Grupo de Pesquisa, 2021.

As principais mídias digitais utilizadas pelos parlamentares são Facebook e Instagram, por seu baixo custo e facilidade de acesso, reproduzindo um padrão também observado nas eleições majoritárias brasileiras (BRAGA; CARLOMAGNO, 2018). Também como no caso das eleições municipais, um percentual reduzido de políticos mantém websites ativos no ar ou usam twitter de forma regular, o que não implica afirmar natualmente que tais midias não sejam relevantes para os políticos organizarem sua comunicação pública. Observamos que o Youtube já é utilizado por cerca de 58,0\% dos deputados estaduais brasileiros, que possuem canais específicos nesta plataforma, ou então perfis de usuários. Desagregando os dados por região, podemos observar uma grande homogeneidade no uso de algumas ferramentas digitais pelos deputados (tais como Facebook, Instagram e Twitter, amplamente difundidas), enquanto outras revelam maior desigualdade, tais como websites, Youtube e, em menor escala, Twitter, como pode ser atestado pela tabela abaixo.

Tabela 01 - Uso de midias digitais por região $(\mathrm{n}=1059)$

\begin{tabular}{|c|c|c|c|c|c|c|c|c|c|c|c|c|}
\hline \multirow[b]{4}{*}{ Facebook } & \multicolumn{12}{|c|}{ Região } \\
\hline & \multicolumn{2}{|c|}{ Coeste } & \multicolumn{2}{|c|}{ Nordeste } & \multicolumn{2}{|c|}{ Norte } & \multicolumn{2}{|c|}{ Sudeste } & \multicolumn{2}{|r|}{ Sul } & \multicolumn{2}{|c|}{ Total } \\
\hline & $\mathrm{N}$ & $\%$ & $\mathrm{~N}$ & $\%$ & $\mathrm{~N}$ & $\%$ & $\mathrm{~N}$ & $\%$ & $\mathrm{~N}$ & $\%$ & $\mathrm{~N}$ & $\%$ \\
\hline & 111 & $98,2 \%$ & 325 & $95,3 \%$ & 177 & $95,7 \%$ & 268 & $98,9 \%$ & 147 & $98,7 \%$ & 1.028 & $97,4 \%$ \\
\hline Instagram & 106 & $93,8 \%$ & 312 & $91,5 \%$ & 159 & $85,9 \%$ & 247 & $91,1 \%$ & 140 & $94,0 \%$ & 964 & $91,3 \%$ \\
\hline Twitter & 86 & $76,1 \%$ & 217 & $63,6 \%$ & 114 & $61,6 \%$ & 200 & $73,8 \%$ & 124 & $83,2 \%$ & 741 & $71,7 \%$ \\
\hline Websites & 75 & $66,4 \%$ & 190 & $55,7 \%$ & 27 & $14,6 \%$ & 243 & $89,7 \%$ & 143 & $96,0 \%$ & 678 & $64,5 \%$ \\
\hline Youtube & 73 & $64,6 \%$ & 141 & $41,3 \%$ & 95 & $51,4 \%$ & 185 & $68,3 \%$ & 119 & $79,9 \%$ & 613 & $61,1 \%$ \\
\hline Total & 113 & 100 & 341 & 100 & 185 & 100 & 271 & 100 & 149 & 100 & 1.059 & 100,0 \\
\hline
\end{tabular}

Fonte: Base de dados do Grupo de Pesquisa, 2021. 
Entretanto, apesar dessa ampla difusão das midias digitais entre os políticos brasileiros, isso não implica afirmar que o problema da "fratura digital" ou do "digital divide" esteja plenamente equacionado, na medida em que permanecem desigualdades no uso das ferramentas digitais, tanto entre partidos, como entre diferentes subgrupos de parlamentares, como veremos adiante, bem como usos qualitativamente distintos das ferramentais mais colaborativas da internet por diferentes segmentos ou frações de parlamentares.

Apresentados estes dados descritivos gerais sobre o uso das mídias digitais por região, podemos abordar nossos problemas centrais: a) em primeiro lugar, identificar quem são os "outliers" ou usuários intensivos (heavy users) de mídias digitais nas diferentes unidades da federação brasileira; b) em segundo lugar, nos aprofundar na análise das características socio-políticas destes outliers, verificando se os mesmos são "outsiders" na política, acumulando capital político predominantemente através das mídias digitais, ou se são políticos estabelecidos, que já tinham um capital político acumulado antes da atual legislatura. Isto posto, resta definir estes conceitos com mais precisão.

No que se refere aos outliers, trata-se de um conceito estatístico e bastante objetivo. Segundo Moretin \& Bussab, obtida uma distribuição interquatílica de um conjunto de dados e caracterizados seus limites superior e inferior, “As observações que estiverem acima do limite superior ou abaixo do limite inferior estabelecidos serão chamadas pontos exteriores e representadas por asteriscos [num boxplot]. Essas são observações destoantes das demais e podem ser o que chamamos de outliers ou valores atípicos" (MORETIN; BUSSAB, 2010, p. 65). Estes outliers ou valores atípicos podem ser obtidos aplicando a fórmula $Q 3+(1,5 \times L)$, onde Q3 representa o terceiro quartil, sendo há um certo consenso estatístico em usar o valor de 1,5 para identificar os casos extremos da distribuição, sendo que L é igual a subtração do limite superior pelo limite inferior o que torna possível identificar aqueles valores que estão muito fora da norma da distribuição (CERVI, 2017). Para a proposta do presente trabalho nos restringimos a analisar apenas os "outliers" superiores, deixando de lado os valores considerados outliers inferiores, já que estes não representam nenhum significado político preciso para o presente estudo. Em nossa análise definiremos os outliers das duas mídias mais utilizadas pelos deputados estaduais, o Facebook e o Instagram. Consideramos os outliers uma medida inicial para medir os deputados heavy users de mídias digitais.

Em relação ao conceito de outsiders, ele tem uma trajetória mais complexa, até chegar a seu amplo emprego recente da ciência política. Barr (2009), ao analisar relações entre os conceitos de populismo, políticos anti-establishment e outsiders, define como outsider aqueles políticos que ascendem associados a partidos novos que tendem a se tornar competitivos. Corrales (2008), olhando para as características do arranjo institucional latino-americano e a ascensão de parlamentares "recém-chegados", define outsider como aqueles candidatos que concorrem ao pleito sem experiência prévia na política. Carreras (2016) afirma que, embora o conceito de político "outsider" 
pareça simples, a literatura da área não convergiu para uma definição unificada do tema. Dessa forma, é possível mapear pela literatura duas linhas gerais para definição de ator político outsider: i) outsiders como atores sem experiência prévia na política ou com experiência limitada; ii) outsiders como atores fora do establishment político e não pertencentes a partidos competitivos (MARENCO; SERNA, 2007; CORRALES, 2008; CARRERAS, 2016).

No caso deste artigo, adotamos uma definição mais simples de outsiders: trata- se de todos os deputados que exerceram o primeiro mandato eletivo como titular na atual legislatura. Assim, não computamos como outsiders parlamentares que estavam sem mandato, mas já haviam exercido algum cargo eletivo anterior, embora não estivessem se candidatando à reeleição nas eleições de 2018. Entretanto, como ainda não concluirmos o levantamento de todos os candidatos que podem ser considerados como outsiders a partir dessa definição mais estrita, nem concluimos a análise mais profunda dos padrões de carreira e de acúmulo de capital político destas categorias de parlamentares, adotaremos como proxy para definir os outsiders os dados sobre os parlamentares que concorreram à reeleição, disponíveis no site do TSE, computando como outsiders todos aqueles políticos que não concorreram à reeleição no pleito de outubro de $2018^{6}$.

Uma boa ilustração mais qualitativa do que compreendemos por outsider, bem como para a compreensão da importância dada por esta categoria de atores às mídias digitais, pode ser encontrada na apresentação que alguns parlamentares fazem de si mesmos em seus perfis constantes nos websites das assembléias legislativas, via de regra elaborado por seus assessores. A título de exemplo, vejamos a apresentação constante no perfil parlamentar do deputado André Fernandes (PSL/CE), que constitui o arquétipo do outlier-outsider, segundo estamos definindo neste artigo:

Em 2016 [o deputado], começou a expressar suas opiniões sobre cultura, religião e política, principalmente na internet, motivando centenas de pessoas, inclusive de outros estados, com alcance de todo o público brasileiro que concorda com os pensamentos e/ou opiniões emitidas pelo então pré-candidato.

Defendendo sempre a família, os bons costumes, a polícia, o cidadão de bem, a legítima defesa, lutando pela redução de impostos, contra a ideologia de gênero, o aborto, as drogas, o politicamente correto e as inversões de valores, André recebeu o convite do Presidente Jair Messias Bolsonaro para ser candidato a Deputado Estadual no estado do Ceará. Mesmo sem dinheiro, sem "apadrinhamento político local" e sem ninguém na família com histórico na política, André Fernandes, com apenas internet e ideias, se candidatou motivado pela população cansada da "mesmice" no cenário político e conseguiu realizar uma campanha limpa e transparente ao lado do então candidato a presidente Jair Messias Bolsonaro, conseguindo assim, votos em todos os municípios do estado, somando 109.742 votos, sendo o Deputado Estadual mais bem votado do Ceará, mais jovem do Brasil (2018) e com a campanha mais barata do Ceará, provando assim que é possível fazer uma política honesta, digna e honrada. Sonhando com um Brasil melhor e sempre lutando sem medir esforços a favor da população, André recebeu, voluntariamente do povo, o apelido de 01 do Bolsonaro no estado do Ceará, o que lhe é motivo de orgulho. O Deputado Estadual André Fernandes

\footnotetext{
${ }^{6}$ Para fins de checagem, efetuamos um teste de correlação na coleta numa amostra de 90 deputados definidos como outliers pelo primeiro critério e os definidos segundo os critérios do TSE, obtendo um V de Cramer de 0,704.
} 
possui mais de 3,5 milhões de seguidores em suas redes sociais (Facebook, Instagram, Twitter, Youtube) e suas postagens ecoam em todo o país" (CEARÁ, 2021, n.p.).

Assim, podemos perceber na redação desse perfil algumas características arquetípicas dos "outsiders", tais como: a) estar no primeiro mandato e não ser candidato à reeleição; b) pauta política conservadora focada nos valores da família e preservação dos costumes tradicionais; c) pertencimento a profissões "emergentes" na atividade política, tais como policiais, militares, sacerdotes e profissionais de comunicação; d) associação da imagem à candidatura do presidente Jair Bolsonaro; e) uso intenso da campanha em mídias digitais; f) não pertencer às grandes agremiações tradicionais do cenário político ou, ao menos, não ter sólida carreira política no seio de tais agremiações. Assim, boa parte da análise posterior se dedicará a verificar se estas características também estão presentes em outros deputados estaduais brasileiros e com qual intensidade.

Outros parlamentares também se apresentam de maneira semelhante a de André Fernandes, enfatizando a importância das mídias digitais na organização de suas campanhas eleitorais. Vejamos o caso do deputado Kelps Lima (Solidariedade-RN):

“Em 2016, concorrendo à sua primeira eleição majoritária, Kelps foi o segundo colocado na disputa para prefeito de Natal, com 47.576 votos, entrando na história como o primeiro candidato a gravar seus vídeos eleitorais $100 \%$ pelo telefone celular. Também inovou ao fazer uma campanha sem carro de som, sem usar papel e gravando seu programa eleitoral de TV usando apenas o seu telefone celular. Embora tenha feito a campanha mais barata e inovadora, suplantou grupos políticos tradicionais da capital do Estado" (RIO GRANDE DO NORTE, 2020, n.p.)

Dessa forma, os próprios parlamentares em seus perfis enfatizam a relação entre o fato de serem "outsiders" na política e uso intenso das mídias sociais em suas campanhas e atuação política, embora naturalmente não apresentem nenhuma definição estatistica ou sociologicamente rigorosa de ambos os coceitos. Esses depoimentos nos permitem definir melhor algumas questões de pesquisa e proposições básicas que estruturam nosso enfoque:

QP01: Quem são os outliers das mídias mais utilizadas pelos deputados estaduais na legislatura, ou seja, Facebook e Instagram? Ou, por outra: quanto deputados são "outliers" ou "heavy users" de mídias digitais nas 27 assembléias legislativas brasileiras?

Procuraremos responder a esta indagação através da construção de "boxplots" dos usuários de mídias digitais dos 27 parlamentos estaduais que constituem nosso objeto de estudo.

QP2? Quais os perfis de carreira e de trajetória desses “outliers"? Eles são estreantes na política ou possuem carreira política consolidada e capital político já acumulado nas instituições representativas tradicionais e estabelecidas? De que partidos eles provém e qual a sua faixa etária? $\mathrm{O}$ fato de serem outliers ou usuários intensivos de mídias digitais teve impacto em sua votação no 
pleito de 2018?

A partir dessas questões de pesquisa mais gerais e dos casos arquetípicos selecionados acima, podemos formular as seguintes hipóteses:

H1: Parlamentares "outliers" usuários de midias sociais possuiem carreira política recente, pertencem com mais frequencia a partidos da nova direita, não foram candidatos à reeleição e são de uma faixa etária mais jovem, tendo entrado mais recentemente na carreira política.

H2: Parlamentares "outliers" foram mais bem votados nas últimas eleições devido ao papel desempenhado nas mídias digitais na última campanha eleitoral, consolidando tendências de campanhas anteriores onde as ferramentas da internet desempenham crescente papel como proxy de acumulação de capital político e eleitoral (BRAGA; CARLOMAGNO, 2018).

H3: Parlamentares outliers nas mídias digitais são também outsiders na atividade política, pertencendo a novos partidos de esquerda e de direita, e não se candidatando à reeleição.

Assim, para usar uma linguagem técnica, temos um "grupo de tratamento" que são os parlamentares outliers e usuários intensos de mídias digitais e um "grupo de controle" (ou seja, os parlamentares situados acima do intervalo de 1,5), a partir dos quais podemos testar nossas hipóteses e verificar a existência de diferenças estatisticamente significativas ou não entre os dois grupos ou, mais substantivamente, a proposição mais geral de que a internet foi um fator efetivo de acumulação de capital político para determinados subgrupos de parlamentares durante a campanha eleitoral e ao longo da atual legislatura. Além disso, esse contraste entre dois grupos nos permitirá mapear algumas características da carreira dos parlamentares que usam mais intensamente as mídias digitais.

Isto posto, podemos passar à análise mais sistemática dos dados coletados durante nossa pesquisa.

\section{Análise dos resultados: o universo dos outliers brasileiros e seus padrões de carreira política e perfis sociais}

Para facilitar a exposição, inicialmente examinaremos os usuários do Facebook, mídia digital mais utilizada pelos deputados estaduais, em seguida do Instagram, uma ferramenta mais recente e que possui características um pouco distintas.

\subsection{Perfil dos outliers do Facebook}

Para definir o universo de outliers do Facebook criamos um índice de presença no Facebook formado pela soma das curtidas e dos seguidores dos perfis dos deputados. Assim procedemos porque algumas vezes há uma pequena diferença entre curtidas e seguidores, pelo que a soma é uma medida que elimina tais defasagens compondo um indice agragado de presença nesta rede social. Os outliers do Facebook podem ser visualizados através do seguinte Boxplot: 
Grafico 03 - Boxplot dos deputados estaduais (presença no Facebook)

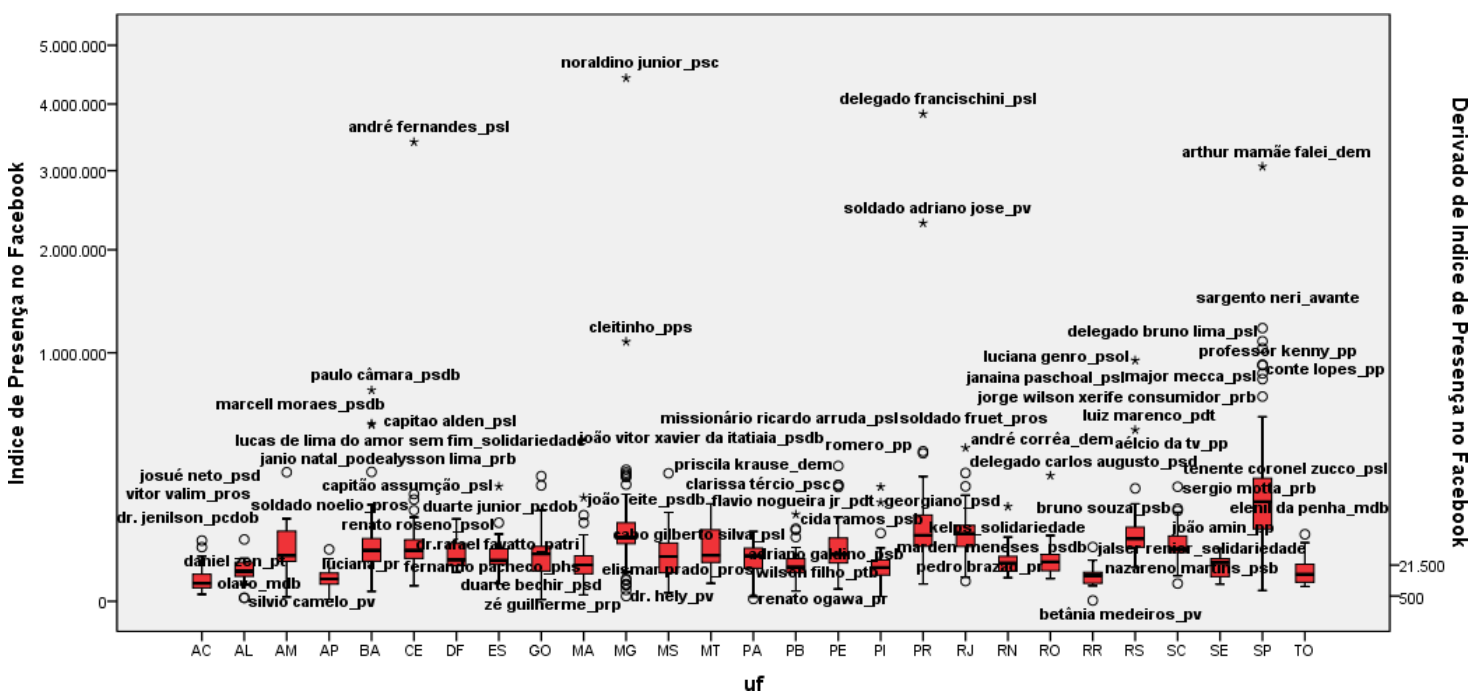

Fonte: Elaboração própria, 2021.

Esse gráfico ilustra a distribuição dos outliers por unidade da federação, obtida a partir dos intervalos interquartílicos de cada estado e Distrito Federal. Podemos visualizar que o deputado com maior índice de presença no Facebook é o deputado Noraldino Júnior, do PSC-MG, seguido pelo deputado Francisco Francischini (PSL-PR), André Fernandes (PSC-CE) e Artur Mamãe Falei (DEM-SP) todos eles com mais de três milhões de seguidores e curtidas no Facebook. A partir da aplicação destes critérios, obtemos um universo de 91 deputados, assim distribuídos regionalmente:

Tabela 02 - Distribuição regional dos outliers (Facebook)

\begin{tabular}{lccccccr}
\hline & & \multicolumn{5}{c}{ Região } & Total \\
\cline { 3 - 6 } & & C. oeste & Nordeste & Norte & Sudeste & Sul & \\
\hline \multirow{4}{*}{ Não-outlier } & $\mathrm{N}$ & 107 & 310 & 172 & 245 & 134 & 968 \\
& $\mathrm{R}$ & $11,1 \%$ & $32,0 \%$ & $17,8 \%$ & $25,3 \%$ & $13,8 \%$ & $100,0 \%$ \\
& $\mathrm{R}$ & 1,3 & $-0,4$ & 0,8 & $-0,7$ & $-0,7$ & \\
\cline { 2 - 6 } Outlier & $\mathrm{N}$ & 6 & 31 & 13 & 26 & 15 & 91 \\
& $\%$ & $6,6 \%$ & $34,1 \%$ & $14,3 \%$ & $28,6 \%$ & $16,5 \%$ & $100,0 \%$ \\
& $\mathrm{R}$ & $-1,3$ & 0,4 & $-0,8$ & 0,7 & 0,7 & \\
\cline { 3 - 7 } Total & $\mathrm{N}$ & 113 & 341 & 185 & 271 & 149 & 1.059 \\
& $\%$ & $10,7 \%$ & $32,2 \%$ & $17,5 \%$ & $25,6 \%$ & $14,1 \%$ & $100,0 \%$ \\
\hline
\end{tabular}

Fonte: Base da dados do Grupo de Pesquisa, 2021.

Verificamos que a distribuição dos outliers do Facebook é simétrica por região. Embora esteja ligeiramente concentrada nas regiões sul e sudeste, estas diferenças não são estatisticamente significativas, ou seja, os resíduos padronizados ajustados estão entre $-1,9$ e $+1,9$. Como se trata de uma medida meramente estatística, esperava-se essa homogeneidade entre as diferentes regiões. 
Entretanto, o mesmo não ocorre com outras veriáveis relacionadas ao perfil social e partidário dos parlamentares. Para verificar tal fenômeno, e dado o excesso de partidos políticos no Brasil, agregaremos os partidos nas seguintes categorias:

1. Nova esquerda: PSOL, Rede. São aqueles partidos que surgiram como cisões ou dissidências de agremiações de esquerda estabelecidas e institucionalizadas, especialmente o PT.

2. Esquerda tradicional: PCdoB, PT, PDT, PSB, PV. Partidos já estabelecidos no parlamento brasileiro desde a redemocratização e atuantes ao longo de várias legislaturas.

3. Centro fisiológico tradicional: MDB; Cidadania; Solidariedade; PHS: PRB; PR; PSD; PRP; PTC; DC; PMN; PRB; PR; Republicanos. Agremiações que apoiaram sucessivos governos de perfil programático diferente ao longo do processo político brasileiro ou que mudaram de nome em função de fracassos eleitorais e sem identidade programática precisa.

4. Centro-direita tradicional: PSDB; PP; DEM; PTB. Partidos de perfil programático mais definido e que com atuação ao longo de diversas legislaturas.

5. Nova direita: NOVO, PSL; PODE; PROS; PATRI; AVANTE; PODEMOS. São agremiações que se originaram recentemente de cisões de agremiações de centro-direita estabelecidas ou serviram de suporte para candidaturas personalistas no plano federal e estadual.

Esta classificação foi baseada nos dados fornecidos pelos estudos recentes mais relevantes sobre a classificação ideológica dos partidos políticos (TAROUCO, 2015), e pelo GPS ideológico da Folha de São Paulo (GPS IDEOLÓGICO, 2020). De uma maneira geral, definimos como "nova esquerda" aqueles partidos surgidos após a ascensao do PT ao governo como consequência de cisões deste partido, e "nova direita" aquelas agremiações originárias da crise dos antigos partidos conservadores após a operação Lava Jato e a ascesão do Bolsonarismo (CRUZ, KEYSEL; CODAS, 2015; ROEDER; BRAGA, 2017). Agregados os dados, podemos obter a seguinte tabela:

Tabela 03 - Distribuição dos outliers por agregados partidários.

\begin{tabular}{lcccr}
\hline \multirow{2}{*}{ Agregados } & & \multicolumn{2}{c}{ Outliers do Facebook } & \multirow{2}{*}{ Total } \\
\cline { 3 - 4 } Nova esquerda & $\mathrm{N}$ & 22 & 4 & 26 \\
& $\%$ & $84,6 \%$ & $15,4 \%$ & $100,0 \%$ \\
& $\mathrm{R}$ & $-1,3$ & 1,3 & \\
\hline \multirow{3}{*}{ Esquerda } & $\mathrm{N}$ & 234 & 17 & 251 \\
& $\%$ & $93,2 \%$ & $6,8 \%$ & $100,0 \%$ \\
& $\mathrm{R}$ & 1,2 & $-1,2$ & \\
\hline \multirow{3}{*}{ Centrão } & $\mathrm{N}$ & 337 & 21 & 358 \\
& $\%$ & $94,1 \%$ & $5,9 \%$ & $100,0 \%$ \\
& $\mathrm{R}$ & 2,3 & $-2,3$ & \\
\hline
\end{tabular}




\begin{tabular}{lcccr}
\hline \multirow{3}{*}{ Centro-direita tradicional } & $\mathrm{N}$ & 242 & 24 & 266 \\
& $\%$ & $91,0 \%$ & $9,0 \%$ & $100,0 \%$ \\
& $\mathrm{R}$ & $-0,3$ & 0,3 & \\
\hline \multirow{3}{*}{ Nova direita } & $\mathrm{N}$ & 133 & 25 & 158 \\
& $\%$ & $84,2 \%$ & $15,8 \%$ & $100,0 \%$ \\
\hline Total & $\mathrm{R}$ & $-3,5$ & 3,5 & \\
\hline
\end{tabular}

Fonte: Base de dados do Grupo de Pesquisa, 2021.

Pelos dados, observamos que o percentual de outliers é superior em partidos da nova direita e da nova esquerda, embora apenas para aqueles partidos os percentuais sejam estatisticamente significativos. Por outro lado, os partidos do centro fisiológico tradicional apresentam percentuais significativamente inferiores de não-outliers. Isso indica que existe um subgrupo de deputados com níveis ainda baixos de uso das ferramentas de comunicação digitais, e que apresentam outras modalidades de acumulação de capital político além daquelas originadas das redes digitais. Observamos ainda o caso de alguns deputados atípicos como, por exemplo, o de Artur Mamãe Falei, de São Paulo, extremamente ativo em várias midias digitais, especialmente o Youtube, mas que foi eleito por um partido de centro-direita tradicional, ou seja, o DEM. Isso mostra que, além da análise quantitativa agregada dos deputados em seu conjunto, são necessários estudos de caso mais aprofundados para analisar cada um dos casos que fogem aos padrões medianos esperados.

Além dos perfis partidários dos outliers e casos normais, podemos contrastar os dois grupos no tocante às médias de idade e média de números de votos recebidos nas eleições, a fim de verificar se os usuários intensivos do Facebook são mais jovens e mais competivivos eleitoralmente. Para isso, faremos um teste $\mathrm{T}$ de médias entre os dois grupos:

Tabela 04 - Médias de idade e votos X presença no Facebook

\begin{tabular}{clcc}
\hline \multicolumn{2}{c}{ Presença no Facebook } & Idade & Votos \\
\hline \multirow{2}{*}{ Não-outlier } & Média & 48,44 & 43.075 \\
& N & 968 & 963 \\
& Desvio Padrão & 12,18 & 72.832 \\
\hline \multirow{2}{*}{ Outlier } & Média & 44,13 & 64.863 \\
& N & 91 & 91 \\
& Desvio Padrão & 10,06 & 72.540 \\
\hline \multirow{2}{*}{ Total } & Média & 48,07 & 44.956 \\
& N & 1.059 & 1.054 \\
& Desvio Padrão & 12,07 & 73.029 \\
\hline
\end{tabular}

$\mathrm{p}$ idade $=0,001 ;$ diferença média idade $=4,31 ; \mathrm{p}$ votos $=0,007 ;$ diferença média votos $=21.78$

Fonte: Base de dados do Grupo de Pesquisa, 2021. 
$\mathrm{O}$ teste $\mathrm{T}$ de médias para amostras independentes acima nos mostra que as médias de idade são inferiores e as de votos dos outliers são significativamente superiores às dos parlamentares nãooutliers, evidenciando que as características desde grupo são distintas entre si. Com efeito, os outliers são mais jovens que os parlamentares comuns, além de terem sido significativamente mais votados no pleito de outubro de 2018 , mostrando que o uso das midias digitais pode ter se configurado com um meio relevante de acumulo de capital político no último pleito.

Resumindo, verificamos que, no caso específico do Facebook, há diferenças significativas entre os subgrupos de outliers e não-outliers: eles estão significativamente concentrados em partidos da nova direita, são significativamente mais jovens e tiveram um número significativamente maior de votos que os não-outliers, embora regionalmente sejam homogêneos. Verificaremos agora se o mesmo ocorre com o Instagram, a segunda mídia mais utilizada pelos deputados.

\subsection{Perfil dos outliers no Instagram}

Podemos agora definir o universo de outliers no Instagram. Ao contrário do que fizemos no Facebook, no entanto, computamos apenas o número de seguidores dos deputados nessa plataforma, que são os dados disponibilizados nesta rede social sobre a presença on-line do político. Os outliers do Instagram podem ser visualizados através do seguinte Boxplot:

Grafico 04 - Boxplot de seguidores no Instagram dos deputados estaduais brasileiros (2019-2020)

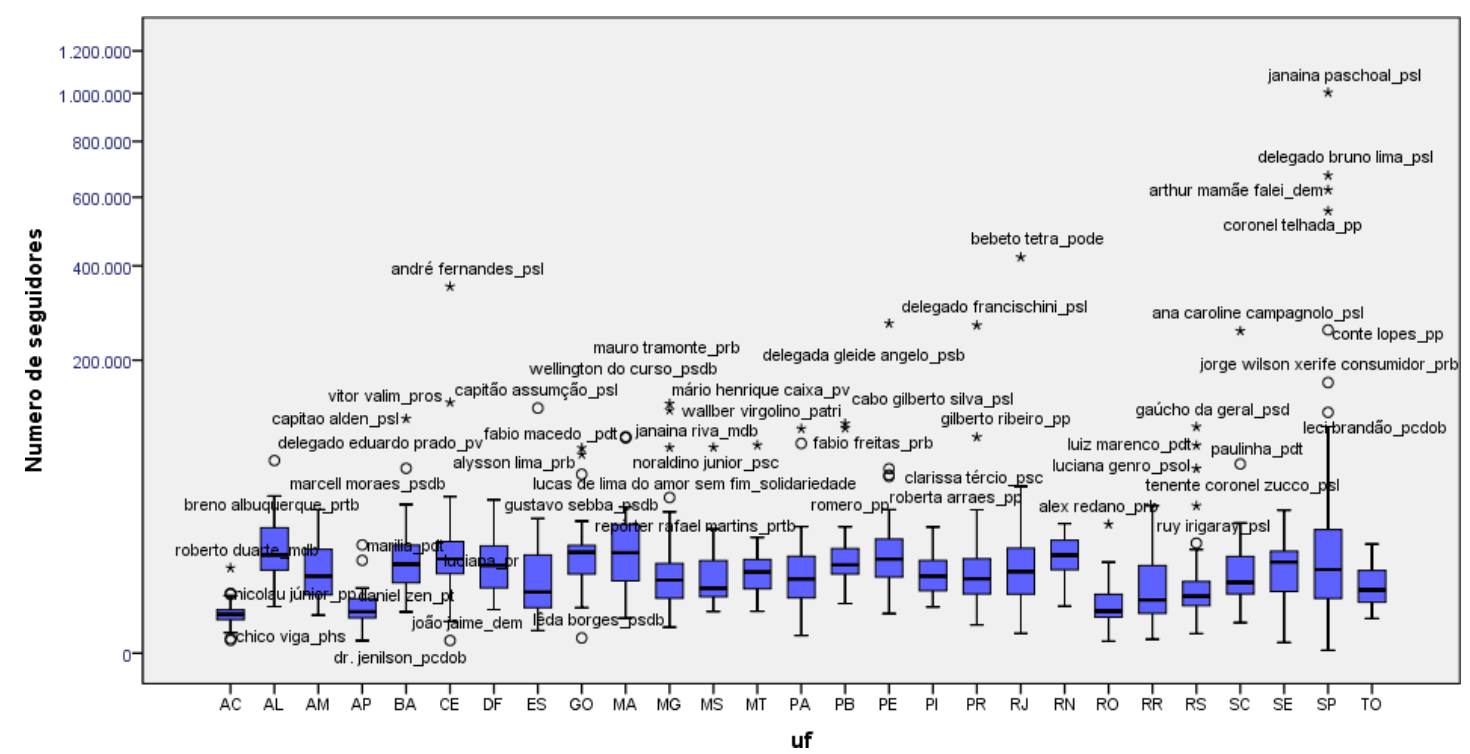

Fonte: Base de dados do Grupo de Pesquisa, 2021.

Esse gráfico ilustra os outliers por estados, obtidos a partir da distribuição interquartílica de cada unidade a federação. Podemos visualizar que o parlamentar com maior índice relativo de presença no Instagram é a deputada Janaina Pascoal (PSL-SP), seguida pelo deputado Bruno Lima (PSL-SP), por Artur Mamãe Falei (DEM-SP), e pelo Coronel Talhada (PP-SP), todos eles eleitos 
pelo estado de São Paulo, onde observamos uma maior concentração de parlamentares outliers, ao contrário do Facebook, sendo que esta é a única unidade da federação com resíduo padronizado maior que 1,9 $(\mathrm{R}$ ajustado = 2,3). A partir da aplicação destes critérios, obtemos um universo de 82 deputados estaduais, assim distribuidos regionalmente.

Tabela 05 - Distribuição Regional dos outliers (Instagram)

\begin{tabular}{cccccccc}
\hline & & \multicolumn{5}{c}{ Região } & \multirow{2}{*}{ Total } \\
\cline { 3 - 7 } & & Coeste & Nordeste & Norte & Sudeste & Sul & \\
\hline Não-outliers & $\mathrm{N}$ & 106 & 321 & 169 & 246 & 135 & 977 \\
& $\%$ & $10,8 \%$ & $32,9 \%$ & $17,3 \%$ & $25,2 \%$ & $13,8 \%$ & $100,0 \%$ \\
& $\mathrm{R}$ & 0,7 & 1,6 & $-0,5$ & $-1,1$ & $-0,8$ & \\
\hline Outliers & $\mathrm{N}$ & 7 & 20 & 16 & 25 & 14 & 82 \\
& $\%$ & $8,5 \%$ & $24,4 \%$ & $19,5 \%$ & $30,5 \%$ & $17,1 \%$ & $100,0 \%$ \\
& $\mathrm{R}$ & $-0,7$ & $-1,6$ & 0,5 & 1,1 & 0,8 & \\
\hline \multirow{5}{*}{ Total } & $\mathrm{N}$ & 113 & 341 & 185 & 271 & 149 & 1.059 \\
\cline { 2 - 6 } & $\%$ & $10,7 \%$ & $32,2 \%$ & $17,5 \%$ & $25,6 \%$ & $14,1 \%$ & $100,0 \%$ \\
\hline
\end{tabular}

Fonte: Base de Dados do Grupo de Pesquisa, 2021.

Assim como no caso do Facebook, não se observa nenhuma diferença regional significativa entre as diferentes regiões do país, evidenciando mais uma vez que já existe uma certa homogeneização da difusão das midias digitais mais utilizadas por todo território nacional. No tocante aos subgrupos partidários, entretanto, podemos observar uma situação um pouco diferente:

Tabela 06 - Distribuição dos outliers por agregados partidários.

\begin{tabular}{|c|c|c|c|c|}
\hline & & \multicolumn{2}{|c|}{ Outliers do Instagram } & \multirow[t]{2}{*}{ Total } \\
\hline & & Não-outlier & Outlier & \\
\hline \multirow{3}{*}{$\begin{array}{l}\text { Nova } \\
\text { esquerda }\end{array}$} & $\mathrm{N}$ & 22 & 4 & 26 \\
\hline & $\%$ & $84,6 \%$ & $15,4 \%$ & $100,0 \%$ \\
\hline & $\mathrm{R}$ & $-1,5$ & 1,5 & \\
\hline \multirow{3}{*}{$\begin{array}{l}\text { Esquerda } \\
\text { tradicional }\end{array}$} & $\mathrm{N}$ & 238 & 13 & 251 \\
\hline & $\%$ & $94,8 \%$ & $5,2 \%$ & $100,0 \%$ \\
\hline & $\mathrm{R}$ & 1,7 & $-1,7$ & \\
\hline \multirow{3}{*}{ Centrão } & $\mathrm{N}$ & 331 & 27 & 358 \\
\hline & $\%$ & $92,5 \%$ & $7,5 \%$ & $100,0 \%$ \\
\hline & $\mathrm{R}$ & 0,2 & $-0,2$ & \\
\hline \multirow{3}{*}{$\begin{array}{l}\text { Centro- } \\
\text { direita } \\
\text { tradicional }\end{array}$} & $\mathrm{N}$ & 250 & 16 & 266 \\
\hline & & $94,0 \%$ & $6,0 \%$ & $100,0 \%$ \\
\hline & $\mathrm{R}$ & 1,2 & $-1,2$ & \\
\hline
\end{tabular}




\begin{tabular}{lcccc}
\hline Nova & $\mathrm{N}$ & 136 & 22 & 158 \\
direita & $\%$ & $86,1 \%$ & $13,9 \%$ & $100,0 \%$ \\
& $\mathrm{R}$ & $-3,2$ & 3,2 & \\
\hline Total & $\mathrm{N}$ & 977 & 82 & 1.059 \\
\cline { 2 - 5 } & & $92,3 \%$ & $7,7 \%$ & $100,0 \%$ \\
\hline
\end{tabular}

Qui-quadrado de Pearson $\mathrm{p}=0,008 ;$ Valor $=13.651$

Fonte: Elaboração própria, 2021.

Pelos dados da tabela acima verificamos um padrão semelhante aos observados no Facebook, com partidos da nova direita tendo um percentual significativamente superior de parlamentares outliers em comparação com as demais correntes partidárias. Entretanto, inversamente ao Facebook, os parlamentares do centro fisiológico estabelecido não possuam um resíduo padronizado significativamente negativo no tocante aos outliers, evidenciando uma distribuição semelhante entre os outliers no tocante a esta categoria partido.

Tabela 07 - Médias de idade e votos X presença no Instagram

\begin{tabular}{clcc}
\hline \multicolumn{2}{c}{ Presença no Instagram } & Idade & Votos \\
\hline \multirow{2}{*}{ Não-outlier } & Média & 48,62 & $40.456,64$ \\
& N & 977 & 972 \\
& Desvio Padrão & 12,09 & $26.418,70$ \\
\hline \multirow{2}{*}{ Outlier } & Média & 41,51 & $98.289,84$ \\
& N & 82 & 82 \\
& Desvio Padrão & 9,71 & $240.505,66$ \\
\multirow{2}{*}{ Total } & Média & 48,07 & $44.956,00$ \\
& N & 1.059 & 1.054 \\
& Desvio Padrão & 12,07 & $73.029,12$ \\
\hline
\end{tabular}

$\mathrm{p}$ idade $=0,000 ;$ diferença de média $=7,11 ;$

$\mathrm{p}$ votos $=0,000 ;$ diferença de média $=57.833,20$

Fonte: Elaboração própria, 2021.

Assim como no caso do Facebook, no Instagram se observam diferenças de média significativas entre os dois grupos, confirmando nossa hipótese anterior. Entretanto, podemos perceber que as diferenças de média entre outliers e não-outliers no caso do Instagram são superiores, indicando que neste caso de uma midia digital de uso mais recente os parlamentares foram mais bem votados e são mais jovens do que no caso do Facebook, o que pode ser um indício de perfis diferentes de uso das duas mídias digitais, uma de uso mais antigo e "estabelecida" outro de uso mais recente por um subgrupo de deputados mais conectados com as inovações digitais.

\subsection{Outliers e outsiders}

Para verificar a terceira hipótese de se os outliers podem ser considerados outsiders ou não, utilizaremos como proxy para a caracterização destes últimos os dados sobre candidaturas à reeleição 
dos políticos disponibilizados nas bases de dados do TSE. Definiremos como outsiders, numa primeira aproximação, aqueles deputados estaduais que não se candidataram à reeleição, ou seja, que não exerceram mandato de deputado estadual na legislatura anterior, e como insiders (ou estabelecidos) aqueles que se recandidataram ao cargo de deputado estadual nas últimas eleições e que foram titulares de mandatos nos quatro anos anteriores. A distribuição entre os deputados estaduais candidatos e não-candidatos à reeleição no pleito de outubro de 2018 por agregado partidário pode ser visualizada na seguinte tabela:

Tabela 08 - Candidatos à reeleição por agregados partidários (outubro de 2018).

\begin{tabular}{lcccc}
\hline & & \multicolumn{2}{c}{ Candidato à reeleição } & Total \\
\cline { 3 - 4 } & & $\mathrm{Não}$ & $\mathrm{Sim}$ & \\
\hline Nova & $\mathrm{N}$ & 20 & 6 & 26 \\
esquerda & $\%$ & 76,9 & 23,1 & 100,0 \\
& $\mathrm{R}$ & 3,1 & $-3,1$ & \\
\hline Esquerda & $\mathrm{N}$ & 97 & 154 & 251 \\
tradicional & $\%$ & 38,6 & 61,4 & 100,0 \\
& $\mathrm{R}$ & $-3,1$ & 3,1 & \\
\hline Centrão & $\mathrm{N}$ & 153 & 205 & 358 \\
& $\%$ & 42,7 & 57,3 & 100,0 \\
\hline Centro- & $\mathrm{N}$ & $-2,0$ & 2,0 & \\
direita & $\%$ & 100 & 166 & 266 \\
tradicional & $\mathrm{N}$ & $-3,6$ & 62,4 & 100,0 \\
& $\mathrm{R}$ & 3,6 & \\
\hline Nova & $\mathrm{N}$ & 129 & 29 & 158 \\
direita & $\%$ & 81,6 & 18,4 & 100,0 \\
& $\mathrm{R}$ & 9,4 & $-9,4$ & \\
\hline Total & $\mathrm{N}$ & 499 & 560 & 1.059 \\
\cline { 2 - 4 } & & 47,1 & 52,9 & 100,0 \\
\hline
\end{tabular}

Fonte: Base de dados do Grupo de Pesquisa, 2021.

Pelos dados acima verificamos que há diferenças significativas entre o percentual de outsiders entre os diferentes agregados partidários. Assim, os partidos da nova esquerda e da nova direita apresentam percentual significativamente superior de deputados que não estavam se candidatando à reeleição, ou outsiders segundo nossa terminologia. Já os partidos da esquerda tradicional, do centrão e da centro-direita tradicional contam com um número signicativamente superior de deputados "estabelecidos", ou seja, que exerceram o mandato de deputado no período imedidatamente anterior ao pleito de outubro de 2018.

Resta agora verificar se o fato do candidato estar postulando a reeleição ou não tem algum efeito sobre o uso de midias digitais mais utilizadas pelos deputados estaduais. 
No tocante ao Facebook, os dados são os seguintes:

Tabela 09 - Outliers do Facebook X Deputados outsiders

\begin{tabular}{lcccc}
\hline & & \multicolumn{2}{c}{ Candidato à reeleição } & Total \\
\cline { 2 - 3 } & & $\mathrm{N}$ & $\mathrm{S}$ & \\
\hline \multirow{2}{*}{ Não-outlier } & $\mathrm{N}$ & 454 & 514 & 968 \\
& $\%$ & 46,9 & 53,1 & 100,0 \\
& $\mathrm{R}$ & $-0,5$ & 0,5 & \\
\hline \multirow{3}{*}{ Outlier } & $\mathrm{N}$ & 45 & 46 & 91 \\
& $\%$ & 49,5 & 50,5 & 100,0 \\
& $\mathrm{R}$ & 0,5 & $-0,5$ & \\
\multirow{3}{*}{ Total } & $\mathrm{N}$ & 499 & 560 & 1.059 \\
\cline { 2 - 4 } & & $\mathbf{4 7 , 1}$ & $\mathbf{5 2 , 9}$ & $\mathbf{1 0 0 , 0}$ \\
\hline
\end{tabular}

Fonte: Base de Dados do Grupo de Pesquisa, 2021.

Pelos dados acima podemos observar que não existe associação significativa entre as situações de outsiders X outliers dos deputados estaduais, na medida em que ser outlier no Facebook não está associado ao fato de ser "estreante" ou "estabelecido" na política. Isso significa que havia um contingente expressivo de deputados "estabelecidos" que já acumulava capital político e social no Facebook durante o exercício do mandato, e que tal acúmulo foi equivalente ao obtido pelos "outsiders" durante as eleições, o que é uma evidência da existência de "campanha permanente" também por deputados estabelecidos nas redes digitais, demonstrando as intuições de estudos anteriores de que a presença nas redes digitais mais utilizadas transformou-se num importante ativo dos políticos no exercício do mandado, usando também durante os pleitos eleitorais (BRAGA et. al., 2017).

Podemos observar abaixo que a situação é bastante distinta no tocante ao Instagram, uma mídia social de uso mais recente entre os deputados e os políticos de uma maneira geral, e que só começou a se difundir nas eleições de 2016 (BRAGA; CARLOMAGNO, 2018).

Tabela 10 - Outliers do Instagram X Deputados outsiders (2019-2020)

\begin{tabular}{lcccc}
\hline & & \multicolumn{2}{c}{ Candidato à reeleição } & Total \\
\cline { 3 - 4 } & & $\mathrm{N}$ & $\mathrm{S}$ & \\
Não- & $\mathrm{N}$ & 448 & 529 & 977 \\
outliers & & 45,9 & 54,1 & 100,0 \\
& $\mathrm{R}$ & $-2,8$ & 2,8 & \\
\multirow{3}{*}{ Outliers } & $\mathrm{N}$ & 51 & 31 & 82 \\
& & 62,2 & 37,8 & 100,0 \\
\multirow{3}{*}{ Total } & $\mathrm{R}$ & 2,8 & $-2,8$ & \\
& $\mathrm{~N}$ & 499 & 560 & 1.059 \\
\cline { 2 - 4 } & & $\mathbf{4 7 , 1}$ & $\mathbf{5 2 , 9}$ & $\mathbf{1 0 0 , 0}$
\end{tabular}

Fonte: Elaboração própria, 2021. 
O teste do Qui-quadrado $(\mathrm{p}=0,004)$ mostra que, no caso do Instagram, há relação entre o fato de o deputado ser outlier e ser outsider, ou seja, aqueles mais presentes nesta mídia social são de fato aqueles que entraram mais recentemente na política. Isso indica que as mídias de uso mais recentes podem ser aquelas mais usadas pelos deputados "outsiders", mais jovens e conectados com novas mídias, de linguagem mais moderna. Esse talvez seja o caso do Whatsapp também. Entretanto, como não é uma mídia pública onde os dados sobre as informações que circulam nas redes sejam de acesso amplo, trata-se de uma hipótese de difícil confirmação ou refutação. Assim, podemos afirmar que nossa terceira hipótese foi parcialmente confirmada.

\section{Conclusões}

Podemos resumir os achados da presente pesquisa e indicar algumas questões para aprofundamento futuro. Verificamos, em primeiro lugar, que o uso das mídias digitais está amplamente difundido entre os deputados estaduais de diferentes regiões do país, tendo estas se tornado uma ferramenta de gerenciamento quotidiano dos mandatos parlamentares, inclusive em nível subnacional, como já mencionado em outros estudos, sendo que Facebook e Instagram são as mídias mais utilizadas (MARQUES; AQUINO; MIOLA, 2015; PEREIRA; SANTOS; ALMEIDA, 2020). Verificamos também inicialmente como, nos próprios perfis dos parlamentares redigidos pelos assessores, aparecem associados o fato de serem outsiders com o fato de serem outliers, pelo que este é um problema que merece ser aprofundado empiricamente. Com efeito, esses próprios parlamentares associam o fato de serem outsiders na política com o uso intensivo das mídias sociais como ferramenta de comunicação e de mobilização política.

A partir das indicações contidas nas declarações destes parlamentares formulamos nossas questões de pesquisa definindo, numa primeira aproximação, como heavy users de mídias digitais, aqueles parlamentares outliers no Facebook e Instagram, redes sociais digitais mais utilizadas pelos parlamentares. Esse procedimento nos permitiu definir um universo empírico inicial de 91 usuários no Facebook e 82 deputados no Instagram, que serviram como "grupos de tratamento" em nossa análise. A partir dessas evidências preliminares elaboramos nossas questões de pesquisa e nossas três hipóteses de trabalho.

Em seguida, procuramos testar nossas duas primeiras hipoteses monstrando que, de fato, os deputados outliers no Facebook e no Instagram apresentam características diferentes daqueles nãooutliers, sendo predominantemene de partidos da "nova direita", de uma geração mais jovem e tendo uma média de votos significativamente superior, sendo que estes fenômenos se manifestam com mais intensidade do caso do Instagram vis-à-vis o Facebook.

Por fim, procuramos testar nossa terceira hipótese monstrando que, no caso do Instagram, os parlamentares outliers, tendem, de fato, a serem "estreantes" na carreira político, sendo que o mesmo não ocorre no Facebook, uma mídia digital mais antiga. 
De uma maneira geral, nossos dados, mesmo que num nível de agregação elevado, indicam um amplo campo de possibilidades de uso das midias digitais pelos deputados, e permitem a formulação de uma série de outras questões de pesquisa. Por exemplo, quais as consequências para a análise de incorporamos outras categorias para definir os deputados heavy users das mídias digitais além do conceito estatístico de outliers? É possível sofisticar o conceito de outsiders, empregando outros critérios mais refinados para o estudo das carreiras políticas dos parlamentares? Como estes avaliam o uso das mídias digitais em seus perfis? Quais as estratégias discursivas utilizadas por subgrupos de políticos e de usuários em suas mídias digitais? A presença pervasiva das tecnologias digitais ao longo do mandato dos parlamentares é suficiente para caracterizar uma situação de "campanha permanente"? Com qual intensidade? Qual o conteúdo das mensagens veiculadas pelos parlamentares em suas midias digitais? Quais os efeitos compósitos de todos estes fenômenos no estabelecimento de relações de representação entre os parlamentares e sua base social? Como os próprios parlamentares estão avaliando este fenômeno? Já é possível observar sinais de "saturação" do uso das midias digitais pelos parlamentares em sua comunicação pública ou este é um fenômeno ainda em ascensão? Uma série de questões a serem abordadas em outros trabalhos no âmbito de nossas investigações coletivas.

\section{Referências}

ALMEIDA, H. N. Representantes, representados e mídias sociais: mapeando o mecanismo de agendamento informacional. 2017. Tese de Doutorado em [Ciência Política]. Belo Horizonte: Universidade Federal de Minas Gerais (UFMG).

ALMEIDA, H. N. “Tamo junto?” Parlamentares e mídias sociais: uma tipologia dos padrões de atuação de deputados federais no Facebook. Sociedade e Cultura. Goiânia, 2020, v. 23, n.1, p.147.

BARROS, A. T. ; BERNARDES, C. B. ; RODRIGUES, M. R. . Atuação Parlamentar Virtual: as estratégias dos Deputados Federais em seus Websites. E-Legis, v. 6, p. 18-42, 2015.

BARR, R. R. Populists, Outsiders and Anti-Establishment Politics. Party Politics, v. 15, n. 1, 2009.

BRAGA, S.; SAMPAIO, R.; CARLOMAGNO, M.; VIEIRA, F.; ANGELI, A.; SUHURT, J.. Eleições online em tempos de big data: Métodos e questões de pesquisa a partir das eleições municipais brasileiras de 2016. Estudos em Comunicação, v. 25, p. 253-285, 2017.

BRAGA, S. S. CARLOMAGNO, M. C. Eleições como de costume? Uma análise longitudinal das mudanças provocadas nas campanhas eleitorais brasileiras pelas tecnologias digitais (1998-2016).

Revista Brasileira de Ciência Política, Brasília, n. 26, p 7-62, 2018.

BRAGA, S. S.; CRUZ, L. C. As tecnologias digitais e o mandato dos representantes: um estudo sobre o uso da internet pelos deputados estaduais brasileiros da 16a legislatura (2007-2011). In: SILVEIRA, Sérgio Amadeu; BRAGA, Sérgio; PENTEADO, Cláudio. (orgs.) Cultura, política e ativismo nas redes digitais. São Paulo: Editora Fundação Perseu Abramo, 2014.

CARRERAS, M. Outsiders and executive-legislative conflict in Latin America (1980-2007). Latin American Politics and Society, v. 56, n.3, p.70-92, 2016.

CEARÁ. ASSEMBLEIA LEGISLATIVA DO ESTADO DO CEARÁ. Deputados: nomes e 
histórico. Disponível em: https://al.ce.gov.br/index.php/deputados/nomes-e-historico/20partidos/415) Aacesso em novembro de 2000.

CERVI, E. U. Manual de métodos quantitativos para iniciantes em Ciência Política. V.1. Curitiba: CPOP-UFPR, 2017.

VELASCO \& CRUZ, S.; KAYSEL, A.; CODAS, G. (Org.). Direita, volver!: o retorno da direita e o ciclo político brasileiro. São Paulo: Editora Fundação Perseu Abramo, 2015.

CODATO, A; LORENCETTI, A; PRATA, B. Elites políticas e representação: uma investigação da literatura contemporânea sobre políticos profissionais. BIB - Boletim de Informação

Bibliográfica, São Paulo, n. 95. 89-105, 2020.

CORRALES, J. Latin America's Neocaudillismo: ex-presidents and newcomers running for President... and winning. Latin American Politics and Society, v. 50, n. 3, p. 1-35, 2008.

DONATELLO, L. M. Y LEVITA, G. ¿Renovación de las elites o renovación de las élites políticas? Los diputados outsiders en los países del Mercosur (2003-2015). Revista de Investigaciones Políticas y Sociológicas, Universidad de Santiago de Compostela, v. 16, n. 2, p.45-64, 2017.

GPS IDEOLÓGICO. Análise do debate político no Twitter. A posição ideológica de 1,8 mil influenciadores no Twitter em 2020. Folha Online, 11 de novembro de 2020. Disponível em: http://temas.folha.uol.com.br/gps-ideologico/reta-ideologica-2020/a-posicao-ideologica-de-1-8mil-influenciadores-no-twitter-em-2020.shtml Acesso em março de 2021.

MARENCO, A. Y SERNA, M. Por que carreiras políticas na esquerda e direita não são iguais? Recrutamento legislativo no Brasil, Chile e Uruguai. Revista Brasileira de Ciências Sociais, v. 22, n. 64, p.93-113, 2007.

MARQUES, F. P. J. A. ; AQUINO, J. A.; MIOLA, E. Deputados brasileiros no Twitter: um estudo quantitativo dos padrões de adoção e uso da ferramenta. Revista Brasileira de Ciência Política, 2015, n. 14, p. 201-225.

MORETTIN, P. A.; BUSSAB, W. O. Estatística básica. São Paulo: Saraiva Educação SA, 2017.

MIGUEL, L. F. Capital político e carreira eleitoral: algumas variáveis na eleição para o Congresso brasileiro. Revista de Sociologia e Política, n. 20, p. 115-134, 2003.

PEREIRA, M. A. G.; SANTOS, M. L.; ALMEIDA, H. N. Representação Política e Internet - Uso das TICs por Membros do Parlamento Brasileiro. Revista Política Hoje, Recife, v. 27, n. 1, p.83104, 2018.

PURBA, K. R.; ASIRVATHAM, David; MURUGESAN, Raja Kumar. An analysis and prediction model of outsiders percentage as a new popularity metric on Instagram. ICT Express, 2020, v. 6, n. 3, p. 243-248.

REHBEIN-SATHLER, A. G.; FERREIRA, H. F. Mandato Digital: uma experiência com utilização de aplicativo. E-Legis. Brasília, v. 13, n. 32, p. 103-119, 2020.

ROEDER, K. M. \& BRAGA, S. Partidos políticos e sistemas partidários. Curitiba: Editora InterSaberes, 2017.

RIO GRANDE DO NORTE. ASSEMBLEIA LEGISLATIVA DO ESTADO DO RIO GRANDE

DO NORTE. Deputados. Disponível em: http://www.al.rn.gov.br/portal/deputados/104/kelps-lima . Acesso em novembro de 2020).

TAROUCO, G. Os partidos brasileiros segundo seus estudiosos: análise de um expert survey.

Civitas, Porto Alegre, v. 15, n. 1, p. 24-39, jan./mar. 2015. Disponível em:

http://revistaseletronicas.pucrs.br/ojs/index.php/civitas/article/view/18077. Acessado em: 10 abr. 2021.

Artigo submetido em: 2021-05-03; Artigo reapresentado em: 2021-05-20; Aceito em: 2021-05-28 